\title{
Critical thinking development: A comparison between the efficiency of mixed technique and a series of mini-lecture, KWL/T-P-S and presentation
}

\author{
Suttipong Boonphadung ${ }^{*}$
}

Faculty of Education, Suan Sunandha Rajabhat University, Thailand

\section{Key Words}

Critical thinking

Efficiency

Mixed technique

Mini-lecture

KWL/T-P-S

Presentation

Pre-service teachers

Received: 13 October 2016

Accepted: 23 January 2017

Published: 21 April 2017

\begin{abstract}
This study was conducted focusing on critical thinking ability development through the application of mixed techniques and a series of mini-lecture, KWL/T-P-S, and presentations. The samples of this study were two groups of 3rd-year pre-service teachers studying in social studies major: 37 students for group 1 and 47 students for group 2. After the instruction was accomplished, an opinion investigation and satisfaction survey were taken. The instruments were (1) a course syllabus based on mixed technique, (2) a critical thinking evaluation form, and (3) opinion investigation and satisfaction survey forms. The statistical treatment used was the calculation of frequency, mean, deviation, and t-test. Consequently, the results of this study were concluded as follows: (1) The pre-service teachers' critical thinking after the implementation of Mixed Technique was not different from that of a series of Mini-Lecture, T-P-S/KWL and Presentation. (2) Their opinions and satisfaction towards the learning activities were positive. That is, they were satisfied with a wide range of teaching methods which was able to sustain their concentration and better support their learning. The development and comparison results yielded a reflection that the teaching methods were of a great practical contribution to make the critical thinking ability thrive among the students' intellectual qualities, and the creation of innovative teaching ideas also playsTP important role in the leverage of further teaching profession and its career path.
\end{abstract}

(C)2017 The Author. Published by TAF Publishing.

\section{INTRODUCTION}

The educational authorities in Thailand have determined a goal of critical thinking development in which Thai students need to be taught to analyze and, then, to be autonomous learners to keep on the dynamism of the learning trend in the 21st century. Especially, growing this quality in pre-service teachers can help them succeed in learning and living in this era with pride in themselves (Gleason et al., 2011). Regarding this, teacher development is part of their policy in the Higher Education Development Plan No. 11 (2012-2016) which realizes the importance of the promotion to critical thinking instruction. Therefore, an attempt to lead this drive to successful practices is dependent on creative teaching within knowingly developed curricula. Elder and Richard (2012) presented that this cognitive quality should be included in curricula and embedded in a variety of courses. Phillips and Carol (2004) also said that the critical thinking is a cognitive property that higher educational institutes have made compulsory to ground their learners. Tripat

\footnotetext{
${ }^{*}$ Corresponding author: Suttipong Boonphadung

${ }^{\dagger}$ Email: suttipong2511@hotmail.com
} 
(2006) showed the following circumstances which urge the support to critical thinking instruction and its importance: (1) When it comes to competitive performance comparison between Thai students and those from many countries, Thai students' quality is often ranked below the bottom borderline. (2) Due to the more rapid flow of massive news updates and knowledge though several communication media, to consume information smartly also needs the critical thinking. Due to the essence of this intelligence, it is convincing that those who possess this ability always have their own paradigms on occurrences, facts and a course of events around them and try to select manipulable solutions to problems Pintrich (2003). Changing teaching methods to serve the development of critical thinking as stated in National Education Act 1999 is a challenge to teachers today as educating students to be smart thinkers who can analyze, solve and share creativity to make the society better is a task with greater endeavor. More importantly, this is a mission requiring continuous action taking for sustainable development as a result. Because the key role of Faculty of Education is to educate pre-service teachers to serve the nation's development, this is a cognitive ability that needs to be grounded in them and improved through class instruction. From all of the above, there are several reasons telling why this property needs to be strengthened and becomes avidly supported these days.

\section{Objectives}

1. To compare the critical thinking ability of the pre-service teachers between after the use of Mixed Technique and a series of Mini-Lecture, KWL/T-P-S and Presentation

2. To investigate the pre-service teachers' opinions and satisfaction towards the learning activities based on Mixed Technique and a series of Mini-Lecture, KWL/T-P-S and Presentation

\section{Hypothesis}

The critical thinking of the group 1 pre-service teachers after the use of Mixed Technique and those in group 2 after the use of a series of Mini-Lecture, KWL/ T-P-S and Presentation is in different levels.

\section{Scope of the Study}

1. The samples of this study were 2 groups of 3rd year pre-service teachers studying in social study major, Faculty of Education, Suan Sunandha Rajabhat University, in the academic year 2014. Within these 2 groups, there were 37 students for group 1 and 47 students for group 2.

2. The independent variables were Mixed Technique and a series of Mini-Lecture, KWL/TP-S and Presentation while the dependent variables were the student's critical thinking, opinions and satisfaction.

3. The activities based on Mixed Technique and a series of Mini-Lecture, KWL/T-P-S and Presentation in Educational Measurement and Evaluation for Social Study Strand Course were accounted as the content scope of this study.

4. The timeframe of this study was October 2014-July 2015 and it was conducted at the Faculty of Education, Suan Sunandha Rajabhat University.

\section{Critical Thinking Concept}

Critical thinking is to think carefully before believing, judging or making a decision and DeYoung (2003) clarified that it is an ability of identifying problems, selecting information or knowledge to solve, raising a hypothesis and making a reasonable conclusion. Facione 
(2006) defined it as process of reasoning and judging based on reliable and correct principles. Nugent and Barbara (2008) added that the reasoning process also helps enable the critical thinking in 3 aspects: (1) Reasoning process is finding a solution and it starts from specifying problems, exploring and selecting alternatives and obtaining a right solution. (2) Making a decision based on reasoning is contemplating on information carefully, using logic to revise and judging the result acquisition. (3) The scientific method is a string of logical process, all of which prevents rushing to a conclusion or judging too quickly without enough facts or knowledge, starting from identifying problems, collecting relevant data, hypothesizing and testing whether the hypothesis is true. In addition, Ennis (1993) proposed that this high quality thinking is to seek for meanings or answers to an inquisition or a phenomenon before acceptance or rejection while Johnson Johnson (as quoted in Incikabi et al.,2013) stated a more detailed viewpoint that it is an ability to express very clinical thoughts which are well refined from careful analysis and evaluation based on facts and reasons. According to Norris and Robert (1989), this type of thinking is decision making process requiring reasons, reflection from belief and results of any doing. Theoretically, Lauer (2005) asserted that this intelligence is part of the cognitive domain in Bloom's taxonomy and it can be considered as a stepping-stone to synthesis and evaluation. From the definition by Patterson (2011:36-37), this intellectual ability is meant to ponder and use information logically for the best decision.

In summary, the critical thinking is the ability to express thoughts, discuss and decide with a rational, deductive and inductive paradigm based on accurate and valid information.

\section{Instruction for Critical Thinking Development}

An important goal of education, as Fahim and Maryam (2012) concluded from several academic publications, is to teach learners to think and Walsh and Richard (1988) led this point to the critical thinking and clarified that teaching learners to think critically can be performed and taught at every level of education and learners of all levels can be benefited without any restriction of readiness, age and maturity. On the other hand, Facione (2006) proposed a fact in a different side that this quality of cleverness is not inborn and to make it thrive in learners is a difficult task.

To unlock the cognitive performance of learners, the skilled critical thinking can be developed through a wide range of supportive activities and some examples proposed by Patterson (2011) area discussion, an idea sharing conversation and argument mapping, which was proved able to enhance discretion of thought. Cottrell (2011) added that making a conclusion is a strategy to practice critical thinking because making a good summary needs enough information, proof, reasons and solid knowledge to support systematically. From research on critical thinking instruction for undergraduates by Kuhn (2000), the students had to think and express ideas about a provided topic of a lesson or knowledge and they were assigned to prove their ideas and give reasons to support. Though they were active to share ideas, they found it difficult to prove, support and judge their thoughts rationally. To this case, Gelder (2005) pinpointed that the lack of understanding on finding evidence and the importance of proof is considered as a cause; therefore, teaching how to prove the workability of ideas or reasons, refer to related facts and sources, differentiate selected evidence, link all the facts to make a complete conclusion and challenge theories and principles rather than following is a strategy to help nurture the students' critical thinking ability Dawson (as quoted in Mulnix, 2012). Oyler and Frank (2014) unfolded examples of activities to empower the critical thinking in Table 1. 
TABLE 1. Examples of critical thinking development activities

\begin{tabular}{ll}
\hline \hline Methods & Explanation \\
\hline Team-Based/Group Learning & $\begin{array}{l}\text { Students are divided into groups and assigned to do a } \\
\text { discussion on a provided topic through inquiry-based } \\
\text { method. This aims to strengthen their teamwork skills } \\
\text { and develop their communicative skills. }\end{array}$ \\
\hline Writing \& Reflection & $\begin{array}{l}\text { Students are given a task to write some explanation } \\
\text { informally, e.g. blog writing. } \\
\text { Experiential Learning }\end{array}$ \\
$\begin{array}{l}\text { This is initiated by Kolb and there are 4 steps of in- } \\
\text { dividual learning: 1) having experience 2) reflecting } \\
\text { or reviewing the experience 3) concluding the experi- } \\
\text { ence and 4) applying the knowledge gained from the } \\
\text { experience. }\end{array}$ \\
\hline Concept Mapping Assessment & $\begin{array}{l}\text { Students are assigned to draw a mind map or a dia- } \\
\text { gram showing their understanding on the relationship } \\
\text { of their learnt content. }\end{array}$ \\
\hline Case-Based Learning & $\begin{array}{l}\text { Students are assigned to read in advance. When the } \\
\text { class begins, a teacher will give a short lecture before } \\
\text { running role-based activities. }\end{array}$ \\
\hline Problem-Based Learning & $\begin{array}{l}\text { A teacher rouses students' interests by raising some } \\
\text { simulated problematic situations where students are } \\
\text { supposed to encounter. Then, the teacher enables } \\
\text { them to identify problems and encourages them to } \\
\text { make inquiries in several aspects and try to seek for } \\
\text { answers themselves through group process and infor- } \\
\text { mation retrieval. }\end{array}$ \\
\hline
\end{tabular}

Kalelioğlu and Yasemin (2014) presented teaching methods for teaching pre-service teachers' critical thinking ability, for example, six thinking hats, brainstorming, Socrates method, Anyone Here an Expert and many more while Ku et al. (2014) introduced a method combining direct instruction and inquiry-based instruction together for the purpose of critical thinking development. Of all the exemplified methods, Sendag and Ferhan (2009) designed online problem-based learning for developing their undergraduates' critical thinking and found theirs was improved. Another research by Hou (2011), Ashaari (2017) and Kongmanus (2016) was a case study involving the relationship between collaborative learning process and a class activity where a discussion after, for instance, watching a movie took place. From this study, he recommended, among learning activities, a powerful discussion can be made in a class under the condition of including it in a role play activity. In this circumstance, it can result to more diverse alternatives to solve a problem. Furthermore, the findings from the research on the development of critical thinking using mind mapping by Harris and Shenghua (2013) unfolded that the experimental group studying with mind maps outperformed the controlled group so, this was concluded that mind maps helped heighten the critical thinking of the students. From the diversity of critical thinking improvement instruction, Brenda et al. (2011) compiled active pedagogical methods which underline learning by doing and are practical for running critical thinking activities and teaching in all class sizes. Below is Think-Pair-Share as an example.

Think-Pair-Share: This was developed by Frank Lyman of the University of Maryland. 
Through Think-Pair-Share, a collaborative strategy, a teacher will pair up students in a class to work together and class sizes will not be of any concern. In addition, it can be used in all levels of classes. The feature of this method is its procedural string of teaching or activity running. First of all, Think is to raise an open-ended question to challenge students' thoughts. In this stage, an additional role of a teacher is to observe their learning behavior while they are pondering. Next, Pair means breaking down the class into units of two students. The role of each one in a partnering unit is to share ideas to each other and try to reach a conclusion as an answer to the question. Finally, Share is the stage where each pair separates into individuals and all the students in the class exchange ideas, discuss the discovered knowledge and make a mutual conclusion as the ultimate answer (Barkley et al., 2014).

From the above review of literature, the researcher used Mixed Techniques to teach the critical thinking to the social study majors, group 1 , and followed the sequential plan as shown in Table 2. For the other group, a series of Mini-Lecture, T-P-S/KWL and Presentation was put into practice. However, the timeframe for these two groups was 36 hours equally.

TABLE 2 . The allocation of time period for the use of Mixed Technique to teach group 1 students

\begin{tabular}{ll}
\hline \hline Mixed Technique's Instruction Plans & Hours \\
\hline Mini-Lecture, T-P-S/KWL and Presentation & 9 \\
Team-Based Learning and Graphic Organizer & 9 \\
Problem-based Learning and Socrates Method & 9 \\
Peer feedback and Socrates Method & 9 \\
\hline \hline
\end{tabular}

\section{METHODOLOGY}

Instruments

The researcher conducted this study by following the activity plans as stated in the course syllabus to develop the critical thinking ability. Then, the critical thinking evaluation form with 6 rating scales and the opinion investigation and satisfaction survey forms with 4 open-ended questions were used. Their content validity was evaluated by 5 experts and the item-level content validity index (I-CVI) and scale-level content validity index (S-CVI) were 0.8-1.00.

\section{Data Analysis}

The results collected after the pre-service teachers' critical thinking development were analyzed with a package software program on statistics and the analyses are as follows: 1. The scoring of critical thinking evaluation was aligned with the criteria in Table 3 and T-test was used to compare the scores after the use of Mixed Technique to those after a series of Mini-Lecture, T-P-S/KWL and Presentation.

2. The investigation for frequency and the analysis on opinions and satisfaction of the preservice teachers after using Mixed Technique instruction were also statistically conducted.

FINDINGS

1. The critical thinking evaluation results of the pre-service teachers, group 1, after using Mixed Technique were at the good level ( 76.16) while the results of those in the other group taught by a series of Mini-Lecture, T-P-S/KWL and Presentation were at the quite good level ( 74.72). 
TABLE 3 . The criteria for critical thinking evaluation and levels

\begin{tabular}{ll}
\hline \hline Score Range & Interpretation \\
\hline $86-100$ & Excellent \\
$81-85$ & Very good \\
$76-80$ & Good \\
$71-75$ & Quite good \\
$66-70$ & Fair \\
$61-65$ & Quite poor \\
$56-60$ & Poor \\
$51-55$ & Very poor \\
$0-50$ & Improvement needed \\
\hline \hline
\end{tabular}

2. The statistical comparison between the critical thinking of both groups after Mixed Technique, for group 1 and a series of Mini-Lecture, T-P-S/KWL and Presentation, for group 2, was displayed in the Table below.

TABLE 4. The comparison of critical thinking between 2 groups

\begin{tabular}{lllll}
\hline \hline Groups of Pre-service Teachers & x & S.D. & T & p-value \\
\hline Group1 & 76.16 & 6.86 & .27 & .75 \\
Group2 & 74.72 & 8.83 & & \\
\hline \hline
\end{tabular}

From the above Table, their thinking abilities developed by Mixed Technique and a series of Mini-Lecture, T-P-S/KWL and Presentation were not statistically different $(\mathrm{t}=.27$, Sig $=.75)$.

3. Their investigated attitudes and satisfaction towards the critical thinking development were identified in 4 main parts according to the 4 open-ended topical questions: good impression, bad impression, further opinions and further application. The written feedback was shown as follow was in Table 5 .

3.1 Good impression: They enjoyed the teaching techniques which made them feel motivated and better understand the lessons. Therefore, while in the class, no one was seen drowsy and bored. The instruction also enlightened them the methods of applying and adapting the learnt knowledge in their daily lives and the activities never made anyone felt being left behind. Besides, that the teacher had strong intention and taught with understanding on their different learning abilities made positive attitudes among them.

3.2 Bad impression: A minority in group 2 had some worry and felt depressed due to too many assignments.

3.3 Further opinions: They were happy while learning with the implemented instruction methods and they created a happy learning atmosphere. Meanwhile, only a few in group 2 requested an additional knowledge on instruction specifically designed for the social study strand.

3.4 Further application: The benefits assimilated from the class and found applicable were the teaching methods that the teacher used, the use of theories to measure and assess learning achievement and the principles of test construction.

\section{DISCUSSION}

Regarding the results of critical thinking development, the sampling groups' improvement was above the criteria of 70\%. This progress was supported in principle by Beyer (Quoted in Romanowski and Ramzi, 2012) in that integrating the critical thinking into content can 
TABLE 5. The feedback of the pre-service teachers of social study major towards learning activities

\begin{tabular}{|c|c|c|c|c|}
\hline \multirow[t]{2}{*}{ Questions } & \multirow[t]{2}{*}{ Feedback } & \multirow[t]{2}{*}{ Number of Students } & \multicolumn{2}{|l|}{ Total } \\
\hline & & & Group1 & Group2 \\
\hline \multirow[t]{3}{*}{ Good Impression } & -Good teaching techniques & 18 & 27 & 45 \\
\hline & $\begin{array}{l}\text {-Strong teaching intention and under- } \\
\text { standing on the students' learning abil- } \\
\text { ities }\end{array}$ & - & 20 & 20 \\
\hline & $\begin{array}{l}\text { The feeling of being valued as part of } \\
\text { class activities }\end{array}$ & - & 15 & 15 \\
\hline \multirow[t]{2}{*}{ Bad Impression } & No bad feeling towards instruction & 28 & - & 28 \\
\hline & Worry due to too many assignments & - & 9 & 9 \\
\hline \multirow[t]{3}{*}{ Further Opinions } & Enjoyable teaching methods & 8 & 8 & 16 \\
\hline & Happy learning atmosphere & 8 & 4 & 12 \\
\hline & $\begin{array}{l}\text { Desire to learn teaching methods used } \\
\text { for social study subjects only }\end{array}$ & - & 2 & 2 \\
\hline Further Application & $\begin{array}{l}\text { Benefits of the perceived and assimi- } \\
\text { lated teaching methods in terms of their } \\
\text { practicality to use in future classes and } \\
\text { achievement assessment }\end{array}$ & 16 & 16 & 32 \\
\hline
\end{tabular}

make an increase to learning achievement. Likewise, the study by Thaithani (2009) disclosed that the students who were able to do questioning based on the six thinking hat technique possessed better critical thinking as their post-test results after the technique had been taught and practiced were higher than those of their pre-test.

The research on the use of mind mapping to develop the critical thinking conducted by Harris and Shenghua (2013) was also a good support as after teaching and running activities with mind maps, the experimental group had higher level of critical thinking than the controlled group. For the work by Kitroongrueng (2010), his study was on the implementation of PCSSC Model (Preparation, Case Presentation, Selection of Solutions, Sharing with Groups and Construction for New Knowledge) to teach the critical thinking of 23 pre-service teachers who were in their 5th year, Primary Education Major, Faculty of Education, Silpakorn University. After learning with this model, their score results rose by .05 level of statistical significance and this increase directly depicted their improved critical thinking.

In spite of the improvement as mentioned above, when comparing these social study majors of group 1 and 2, their results of the critical thinking development were ranged in the same level. Ku et al. (2014) conducted the research on experimenting 3 modes of instruction: 1) direct approach with minimum inquiry-based approach 2) the balance between direct approach and inquiry-based approach and 3) inquiry-based approach and minimum direct approach. Through the 3 teaching modes, the experimental could perform the critical thinking better than the controlled group.

2. That the students' feedback on the teaching methods, the learning environment, further application of the gained knowledge and the critical thinking assessment used in the course was positive could assure the success in both effectiveness and efficiency of the instruction. That is, the level of satisfaction, in addition to the learning achievement, is also a good indicator that measures the quality of learning management as supported by Ciobanu and Livia (2014) that voices made by participants or learners can be used to consider the 
quality of instruction. The high and very high levels of satisfaction mean the greater success and achievement of learners. In turn, the deterioration of learners' satisfaction to the low and very low levels yields a picture of the imbalance between the academic needs and the academic assistance.

The findings of the study conclude that:

\section{CONCLUSION}

1. Because the teaching methods used in this study emphasize the students' hands-on experience and construct knowledge through learning by doing, how effectively a teacher runs major and minor learning activities and how well a teacher prepares related worksheets, practices and tests for a pre-activity, while-activity and post-activity in a coherent manner are a key to students' success in learning.

2. The evaluation with 6 rating scales, starting from $0-6$, plus explanation for each is designed for undergraduate level only. In case of further use, it can be adapted appropriate to different levels of students.

3. From the positive feedback of the students towards the methods and activities, this makes a point that the instruction in this study can be of a good contribution to develop learner's affective domain which is also as important as psychomotor and cognitive domains.

\section{LIMITATIONS AND RECOMMENDATIONS}

This study is having some limitations and to overcome those following suggestions are being given.

1. Other types and levels of thinking, for example, evaluation, synthesis and creativity, should be also developed and trained through further instructional approaches.

2. Factors or components related to the development process or skills supportive to thinking ability of pre-service teachers should be investigated.

3. The rating scales for evaluation can be redesigned by, for example, adding more scales to investigate deeper or different details for the critical thinking comparison in more detailed aspects.

4. Research with an aim to develop an instructional manual which is on pedagogical methods for thinking process improvement and for pre-service and in-service teachers of all levels and types of education should be conducted.

5. Curriculum development to strengthen both critical thinking and content learning integratively should be researched and conducted for all levels and types of education.

\section{REFERENCES}

Arun, Kumar T. 2006. Coping with Innovative technology: Albert Borgmann on how does technology change learning and teaching in formal and informal education. URL: https://goo.gl/YAAZO9

(accessed May 14, 2017).

Ashaari, Muhamad F. 2017. The adoption and adaptation of online learning models in the framework of online da'wah. International Journal of Humanities, Arts and Social Sciences 3, no. 1: 1-8. D0I: 10.20469/ijhss.3.20001-1

Barkley, Elizabeth FK., Patricia Cross, and Claire Howell Major. 2014. Collaborative learning techniques: A handbook for college faculty. Francisco, CA: Jossey-Bass. DOI: 10.1080/0729436042000235409

Ciobanu, Alina, and Livia Ostafe. 2014. Student satisfaction and its implications in the process of teaching. Acta Didactica Napocensia 7, no. 4: 31-36.

Cottrell, Stella. 2011. Critical thinking skills developing effective analysis and argument. 2nd ed. New York. NY: 
Pal- grave Macmillan.

DeYo ung, Sandra. 2003. Teaching strategies for nurse educators. Upper Saddle River, NJ: Prentice Hall.

Elder, Linda, and Richard Paul. 2012. Critical thinking: Competency standards essential for the cultivation of intellectual skills, part 4. Journal of Developmental Education 35, no. 3: 30-31.

Ennis, Robert H. 1993. Critical thinking assessment. Theory into Practice 32, no. 3: 179-186.

Facione, Peter A. 2006. Critical thinking: What it is and why it counts. URL: https://goo.gl/yVikxB

(accessed December 14, 2016).

Fahim, Mansoor and Maryam Pezeshki. 2012. Manipulating critical thinking skills in test taking. International Journal of Education 4, no. 1: 153-160.

Gelder, Tim V. 2005. Teaching critical thinking: Some lessons from cognitive science. College Teaching 53, no. 1: 41-48.

Gleason, Brenda L., Michael J. Peeters, Beth H. Resman-Targoff, Samantha Karr, Sarah McBane, Kristi Kelley, Tyan Thomas, and Tina H. Denetclaw. 2011. An active-learning strategies primer for achieving ability-based educational outcomes. American Journal of Pharmaceutical Education 75, no. 9: 1-12.

Harris, Charles, and Shenghua Zha. 2013. Concept mapping: A critical thinking technique. Education 134, no. 2: $207-211$. Hou, Huei-Tse. 2011. A case study of online instructional collaborative discussion activities for problem-solving using situ- ated scenarios: An examination of content and behavior cluster analysis. Computers \& Education 56, no. 3: $712-719$. DOI: $10.1016 /$ j.compedu.2010.10.013

Kalelioglu, Filiz, and Ya semin Gülbahar. 2014. The effect of instructional techniques on critical thinking and critical thinking dispositions in online discussion. Educational Technology \& Society 17, no. 1: 248-258.

Kitroongrueng, P. 2010. The development of an instructional model using case based learning based on science of teaching to enhance student teachers' critical thinking. Doctoral thesis, Silpakorn University, Bangkok, TH.

Kongmanus, Kobsook. 2016. Development of project-based learning model to enhance educational media business ability for undergraduate students in educational technology and communications program. Journal of Advances in Humanities and Social Sciences 2, no. 5: 287-296. DOI: 10.20474/jahss-2.5.5

Ku, Kelly YL., Irene T. Ho., Kit-Tai Hau, and Eva CM. Lai. 2014. Integrating direct and inquiry-based instruction in the teach- $\quad$ ing of critical thinking: An intervention study. Instructional Science 42, no. 2: 251-269.

Kuhn, Deanna. 2000. Metacognitive development. Current Directions in Psychological Science 9, no. 5: $178-181$.

Lauer, Thomas. 2005. Teaching critical-thinking skills using course content material: A reversal of roles. Journal of College

Science Teaching 34, no. 6: 34-37.

Mulnix, Jennifer W. 2012. Thinking critically about critical thinking. Educational Philosophy and Theory 44, no. 5: 464- 479.

Norris, Stephen P., and Robert H. Ennis.1989. Evaluating critical thinking. Pacific Grove, CA: Midwest Publications.

Nugent, Patricia M., and Barbara Ann V. 2008. Fundamental success: A course review applying critical thinking to test taking. USA: F. A. Davis Company.

Oyler, Douglas R., and Frank Romanelli. 2014. The fact of ignorance: Revisiting the Socratic method as a tool for teaching

critical thinking. American Journal of Pharmaceutical Education 78, no. 7: 1-9.

Patterson, Fiona J. 2011. Visualising the critical thinking process. Issues 95: 37-41.

Phillips, Virginia, and Carol Bond 2004. Undergraduates' experiences of critical thinking. Higher Education Research \& Development 23, no. 3: 277-294.

Pintrich, Paul R. 2003. A motivational science perspective on the role of student motivation in learning and teaching contexts. Journal of Educational Psychology 95, no. 4: 667-686.

Romanowski, Michael H., and Ramzi Nasser. 2012. How critical thinking is taught in Qatari independent schools' social stud- ies classrooms: Teachers' perspectives. International Journal of Education 4, no. 1: 68-92.

Şendağ, Serkan, and H. Ferhan Odabaşı. 2009. Effects of an online problem based learning course on content knowledge acquisition and critical thinking skills. Computers \& Education 53, no. 1: 132-141.

Thaithani, P. 2011. The effect of six thinking hats questioning based approach using to critical thinking of teacher students. Journal of Education, Nakhon Ratchasima Rajabhat University 3, no. 1: 4-12.

Tripat, A. 2006. Handbook for teaching critical thinking. 2nd ed. Khon Kaen, TH: Khon Kaen University Press. 
Walsh, Debbie, and Richard W. Paul. 1988. The goal of critical thinking: From educational ideal to educational reality. American Federation of Teachers, Washington, D.C., WA.

— This article does not have any appendix. - 